\title{
A Rare Case of Radiologically
} Not Distinguishable Coexistent Meningioma and Vestibular Schwannoma in the

\section{Cerebellopontine Angle - Case Report and Literature Review}

\author{
Juergen Grauvogel ${ }^{\mathrm{a}} \quad$ Tanja Daniela Grauvogel ${ }^{\mathrm{b}}$ \\ Christian Taschner ${ }^{c}$ Sandra Baumgartner ${ }^{d}$ \\ Wolfgang Maier $^{\mathrm{b}}$ Jan Kaminsky ${ }^{\mathrm{a}}$
}

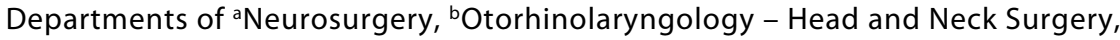
'Neuroradiology, and d Neuropathology, Albert-Ludwigs-University of Freiburg, Freiburg, Germany

\section{Key Words}

Vestibular schwannoma - Meningioma - Cerebellopontine angle surgery

\begin{abstract}
Background: The simultaneous occurrence of cerebellopontine angle (CPA) meningioma and vestibular schwannoma (VS) in the absence of neurofibromatosis type 2 or history of irradiation is very rare. We report a case with coexistent CPA meningioma and VS, which were radiologically not distinguishable in preoperative imaging.

Case Description: A 46-year-old female presented with acute hearing loss, tinnitus and gait ataxia. Otorhinolaryngological diagnostic workup and imaging studies showed an intra- and extrameatal homogenous contrast enhancing lesion. The neuroradiological diagnosis was VS. The patient was operated via the retrosigmoid approach. Intraoperatively two distinct tumors were found: a small, mainly intrameatally located VS and a larger meningioma originating from the dura of the petrous bone. Both tumors were completely microsurgically removed. The patient experienced no new neurological deficit after surgery; particularly facial nerve function was completely preserved. Histopathological examination revealed a fibromatous meningioma and a VS, respectively.
\end{abstract}

Conclusions: The coincidental occurrence of CPA meningioma and VS is very rare. Careful interpretation of imaging studies before surgery is crucial. Even such rare cases should be kept in mind when discussing the therapeutic options with the patient. More 


\begin{tabular}{l|l|l|l} 
Cose Reports in & Case Rep Neurol 2010;2:111-117 & Published online: August 27, 2010 & $\begin{array}{l}\text { ○ 2010 S. Karger AG, Basel } \\
\text { ISSN 1662-680X } \\
\text { wol: 10.1159/000320213 }\end{array}$ \\
& & & \\
\hline
\end{tabular}

studies are needed for a better understanding of mechanisms leading to multiple tumor growth.

\section{Introduction}

Meningioma and vestibular schwannoma (VS) are the most and second most common intracranial benign tumors. In the cerebellopontine angle (CPA) these tumors comprise $6-15 \%[1,2]$ and $80 \%[1,3,4]$, respectively, of all tumors. While the occurrence of these brain tumors in one patient is well known in phakomatoses, as for example in neurofibromatosis type 2 (NF-2), or with a history of previous irradiation of the brain [5, $6]$, it is a very rare condition without these circumstances. There are few published cases in the literature reporting intracranial meningioma combined with schwannoma in the same patient $[6,7]$, and only 5 cases of meningioma and VS in the same CPA are reported (table 1).

In the present paper, a case of coexisting CPA meningioma and VS on the left side in a 46-year-old woman, who was operated in our department, is reported. The literature of previous reported cases of meningioma associated with schwannoma in the absence of NF-2 is reviewed and possible proposed mechanisms leading to the development of two different tumor types in one patient are discussed.

\section{Case Report}

A 46-year-old woman presented to the department of Otorhinolaryngology and Head and Neck Surgery with a history of acute hearing loss and intermittent tinnitus on her left side as well as slight gait ataxia for several weeks. Pure tone audiometry and speech discrimination score showed left-sided deafness and normal hearing on the right side. Electronystagmography revealed reduced excitability of the left vestibular organ. Neurological examination was unremarkable except for deafness on the left ear and a slight gait ataxia. There were no clinical cutaneous signs pointing to the diagnosis of NF-2. The family history for NF-2 was also unremarkable. After the clinical workup was finished, MRI and CT imaging of the cerebrum were performed.

MRI of the brain with and without gadolinium contrast showed a homogenous contrast-enhancing tumor in the internal auditory meatus with extension in the CPA. The tumor portion in the CPA showed broad attachment to the dura of the petrous bone. There were no differences in contrast enhancement of the tumor (fig. 1). CT scan showed a widening of the internal auditory canal and no calcifications within the tumor (fig. 1). The neuroradiological diagnosis was intra- and extrameatal VS.

After the neuroradiological diagnosis of a VS was established, the patient was transferred to the neurosurgical department to be operated via the lateral suboccipital approach because of the large extrameatal tumor growth.

A lateral suboccipital craniectomy on the left side was performed, the cerebellomedullar cistern was opened, the cerebellum retracted and finally the CPA exposed under the operating microscope. It revealed two distinct tumors, a small VS and a meningioma with clear broad attachment to the dura of the petrous bone. The meningioma was located a little above and anterior of the VII and VIII cranial nerves. Both tumors could be completely removed under neurophysiological monitoring. The postoperative course of the patient was uneventful, the patient showed no new neurological deficit after surgery; particularly facial nerve function was completely preserved (House and Brackmann grade I). The patient could be discharged home on the sixth postoperative day.

Histopathological workup of both tumor samples confirmed the diagnosis of fibromatous meningioma and VS, respectively (i.g. 2,3 ).

MR imaging studies performed 3 months after surgery showed complete removal of both tumors and no signs of tumor recurrence. 


\begin{tabular}{l|l|l|l} 
Case Reports in & $\begin{array}{l}\text { Case Rep Neurol 2010;2:111-117 } \\
\text { DOI: } 10.1159 / 000320213\end{array}$ & Published online: August 27, 2010 & $\begin{array}{l}\text { ○ 2010 S. Karger AG, Basel } \\
\text { ISSN 1662-680X } \\
\text { www.karger.com/crn }\end{array}$ \\
\hline
\end{tabular}

\section{Discussion}

VSs are benign intracranial tumors that originate from Schwann cells along the vestibular portion of the eighth cranial nerve. They represent approximately $10 \%$ of all intracranial tumors and more than $80 \%$ of CPA tumors [3,4]. Meningiomas arise from the dural coverings of the brain and are the most common benign intracranial tumors, accounting for $13-26 \%$ of all primary intracranial tumors [8]. They comprise approximately $10-15 \%$ of all CPA tumors [1].

Multiple primary brain tumors are common in patients with phakomatoses, such as NF-2 $[9,10]$. NF-2 is an autosomal dominant inherited disease with an incidence of less than 1 in 25,000 people [11]. The diagnosis of NF-2 is made clinically, and the current diagnostic criteria for NF-2 are met when an individual has either characteristic bilateral VSs or a first-degree relative with NF-2 and one of the following: a unilateral VS before the age of 30 years or the presence of 2 tumors (neurofibroma, meningioma, glioma, schwannoma, or juvenile posterior subcapsular lenticular opacity) $[3,12]$. Furthermore, the pathogenetic mutation in the NF-2 gene on chromosome 22 can be identified by genetic testing [13].

VSs in NF-2 patients more commonly show a lobular pattern, a higher cellularity, and an association with meningeal proliferation. In contrast, unilateral VSs infrequently display a lobular pattern, normally have lower cellularity and abnormal vasculature, and are not associated with meningiomas [3].

There are also some reports in the recent literature of so-called mixed tumors in NF-2 patients, meaning the co-existence of meningioma and schwannoma as two distinct histological components within the same tumor $[3,10]$. A previous history of irradiation is another well-known cause for the development of multiple primary brain tumors [3, 14].

Our patient has had no family history and no clinical or radiological signs of neurofibromatosis, although the patient was not tested genetically for NF-2. There was also no history of irradiation.

The occurrence of two separate histologically different tumors in one patient in the absence of the above mentioned conditions is extremely rare [5]. There are to our knowledge only 5 cases in the literature describing meningioma and VS occurring together in the same CPA [15-19] (table 1). In most of these cases, the preoperative radiological imaging already revealed the presence of two distinct tumors, either because the tumors were located clearly distant of each other and showed the typical radiological signs of either meningioma or VS, or because of different contrast enhancement patterns $[16,18,19]$. VSs invade and expand the acoustic canal, tend to be more regular in appearance and are internally less homogenous. Meningiomas are implanted asymmetrically on the internal auditory canal with an irregular external surface and show broad contact with the skull base, along the petrous bone, or the tentorium. The internal auditory canal is not widened, and tumoral tissue rarely extends into the internal auditory canal. Internal contrast enhancement is usually uniform. Calcification and cystic changes are frequent [18].

In the presented case, the radiological differentiation of two separate tumors had not been possible before surgery. Our neuroradiologists described the tumor as a VS, since there was a widening of the internal auditory canal and a clear intrameatal contrast enhancement. No differentiation could be made by means of the character of contrast enhancement. No calcifications were seen on imaging studies. 
Surgery clearly revealed two distinct tumors in the left CPA: a small, mainly intrameatally located VS and a larger meningioma, located a little anterior and above, with broad contact to the dura of the petrous bone. These findings were confirmed by histopathological examination. The large tumor was found to be a fibrous meningioma with typical features (fig. 2a); the small intrameatal tumor was classified as a schwannoma with histopathologically typical Antoni A and Antoni B areas (fig. 2b). Tibor Pap silver stain showed the typical fine fiber reticulin network in VS tissue, but not in meningioma tissue (not shown).

Immunohistochemical studies showed clearly positive immunoreactivity for vimentin and epithelial membrane antigen (EMA) in fibrous meningioma, whereas it did not in VS. Furthermore, immunohistochemical stain revealed S-100 protein positive cells in schwannoma tissue and only a weak positive reaction in meningioma tissue (fig. 3 ).

Preservation rates and predicting factors for preservation of hearing and facial nerve function are also different in VSs and meningiomas [20]. Hearing preservation rates are usually higher after removal of a CPA meningioma because of the extradural origin of meningiomas [2]. The chance of preserving the facial nerve depends on the tumor size, the topographical relationship between tumor and facial nerve, and preoperative facial nerve function [20].

Radiosurgery is an alternative treatment option particularly for smaller VSs not compressing the brainstem or causing hydrocephalus [21]. Selectivity of radiosurgery depends on the biological differences in the response of different tissues [21], for example concerning tumor regression, which is most common with schwannomas [21], or the role of fractionated radiation therapy [22].

The above mentioned facts stress the importance of establishing a correct radiological diagnosis before offering surgery or radiosurgery to the patient, and of giving the patient the best counseling concerning the risks of both treatment options.

There have been several theories trying to explain the coincidence of two completely separate primary brain tumors in the absence of conditions like phakomatoses or previous brain irradiation: (1) tumors can develop entirely coincidentally; (2) the initial tumor can act as a stimulus on the surrounding cerebral parenchyma or meningeal tissue to induce a new tumor in a different tissue; (3) a carcinogenic stimulus may develop tumors in different tissues simultaneously; or (4) a residual embryonic structure becomes the basis for subsequent multiple brain tumor development [5]. Furthermore, Tsukamoto et al. [6] discussed the association of meningioma and neurinoma, which could be determined genetically, since the genes responsible for the occurrence of these tumors are both located on chromosome 22. However, Tsukamoto et al. did not perform a gene analysis in their patient. This theory could also be true for our patient.

Finally, we suggest that the combination of a CPA meningioma and a VS occurred most likely incidentally. However, the influence of some tumor growth factor forcing the second tumor to grow is theoretically possible in our case, since the tumors were located nearby in the same CPA. More research on possible mechanisms has to be done to support this theory.

In conclusion, meningioma and VS may very rarely occur coincidentally in the same $\mathrm{CPA}$. These tumors can usually be safely and completely removed with a single surgical suboccipital approach. Preoperative imaging studies should be read carefully to establish the diagnosis of two different tumors in order to plan the surgical procedure and to offer the best treatment plan to the patient. The very rare cases of two different primary brain 


\begin{tabular}{l|l|l|l}
$\begin{array}{c}\text { Cose Reports in } \\
\text { Revloiojy }\end{array}$ & $\begin{array}{l}\text { Case Rep Neurol 2010;2:111-117 } \\
\text { D01: 10.1159/000320213 }\end{array}$ & & $\begin{array}{l}\text { Published online: August 27, 2010 S. Karger AG, Basel } \\
\text { ISSN 1662-680X } \\
\text { www.karger.com/crn }\end{array}$ \\
\hline
\end{tabular}

tumors which lie adjacent to each other and which are not distinguishable on preoperative imaging must also be kept in mind when counseling the patient about the risks of the surgical procedure.

\section{Conflict of Interest}

The authors declare that they have no conflict of interest.

Table 1. Summary of previously reported cases of coexistent CPA meningioma and VS

\begin{tabular}{lllll}
\hline Author & Year & $\begin{array}{l}\text { Tumor } \\
\text { side }\end{array}$ & $\begin{array}{l}\text { Sex } \\
\text { Sex }\end{array}$ & $\begin{array}{l}\text { Radiological differentiation of two distinct } \\
\text { tumors on preoperative imaging studies }\end{array}$ \\
\hline Gardner and Turner [15] & 1939 & Left & $48 / \mathrm{F}$ & Not possible (only Roentgenograms available) \\
Thomassin et al. [17] & 1991 & Right & 64/F & Not possible \\
Wilms et al. [18] & 1992 & Right & $47 / \mathrm{F}$ & Possible \\
Chandra and Hedge [19] & 2000 & Right & 35/F & Possible \\
Izci et al. [16] & 2007 & Left & 57/F & Possible \\
Present case & 2010 & Left & $46 / \mathrm{F}$ & Not possible \\
\hline
\end{tabular}

Fig. 1. Axial (a) and coronal (b) T1-weighted gadolinium-enhanced MR images showing a

homogeneous contrast-enhancing intrameatal (arrow) and extrameatal (arrowhead) tumor in the left CPA. Native bone window CT scan (c) shows widening of the left internal auditory canal (arrow) and no calcifications within the tumor.
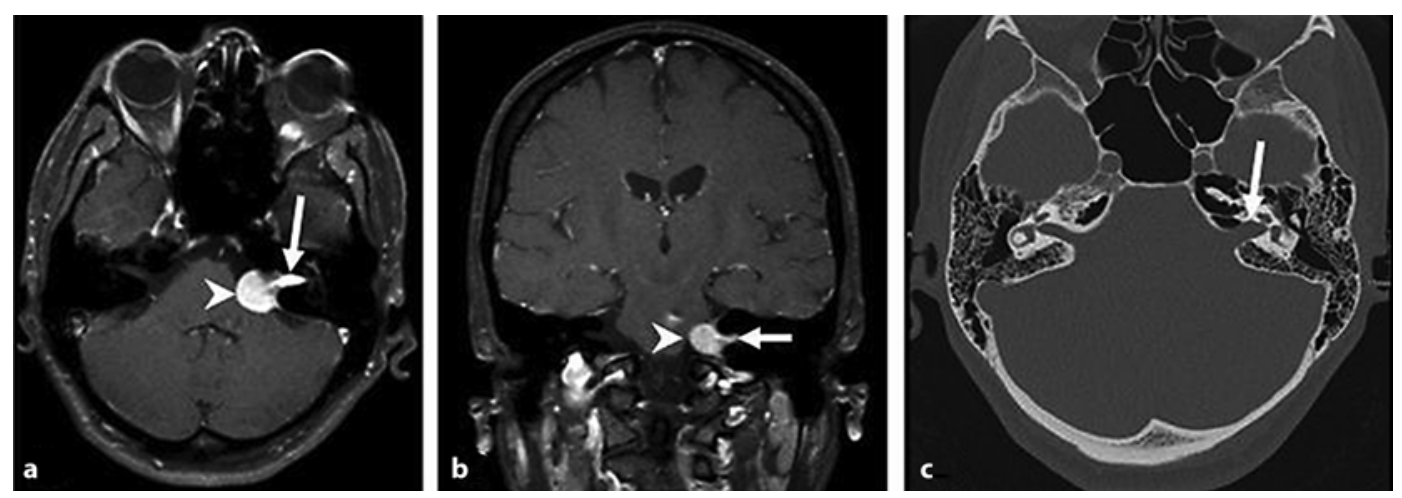


\begin{tabular}{l|l|l|l} 
Cose Reports in & $\begin{array}{l}\text { Case Rep Neurol 2010;2:111-117 } \\
\text { D0I: } 10.1159 / 000320213\end{array}$ & Published online: August 27, 2010 & $\begin{array}{l}\text { @ 2010 S. Karger AG, Basel } \\
\text { ISSN 1662-680X } \\
\text { www.karger.com/crn }\end{array}$ \\
\hline
\end{tabular}

Fig. 2. a Hematoxylin-eosin staining showing the typical patterns of a fibromatous meningioma with central clearing $(\uparrow \downarrow)$ and psammoma body $\left({ }^{* *}\right)$. b Hematoxylin-eosin staining showing the typical features of a VS with Antoni A (A) and Antoni B (B) areas.
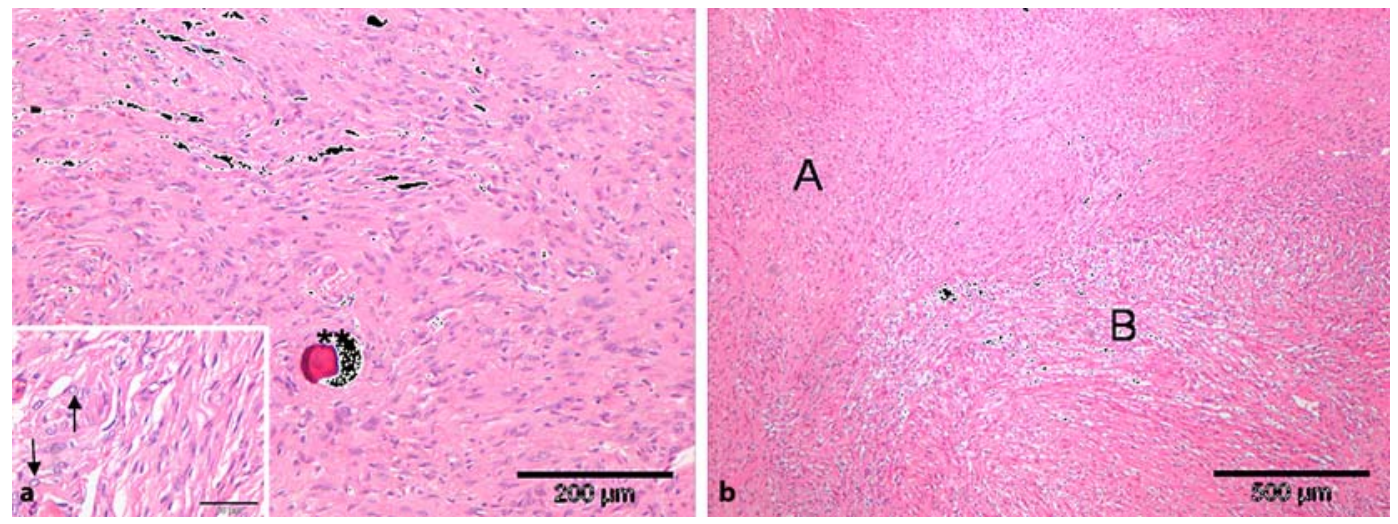

Fig. 3. Immunohistochemical studies showing a clearly positive reaction for vimentin in the meningioma (a) and, for the most part, a negative immunoreactivity for vimentin in the VS (b); a pronounced diffuse-positive reaction for epithelial membrane antigen (EMA) in the meningioma (c) and a negative reaction for EMA in the VS (d); a for the most part negative immunoreactivity for S-100 in the meningioma (e) and a clearly positive reaction for S-100 immunohistochemistry in the VS (f).
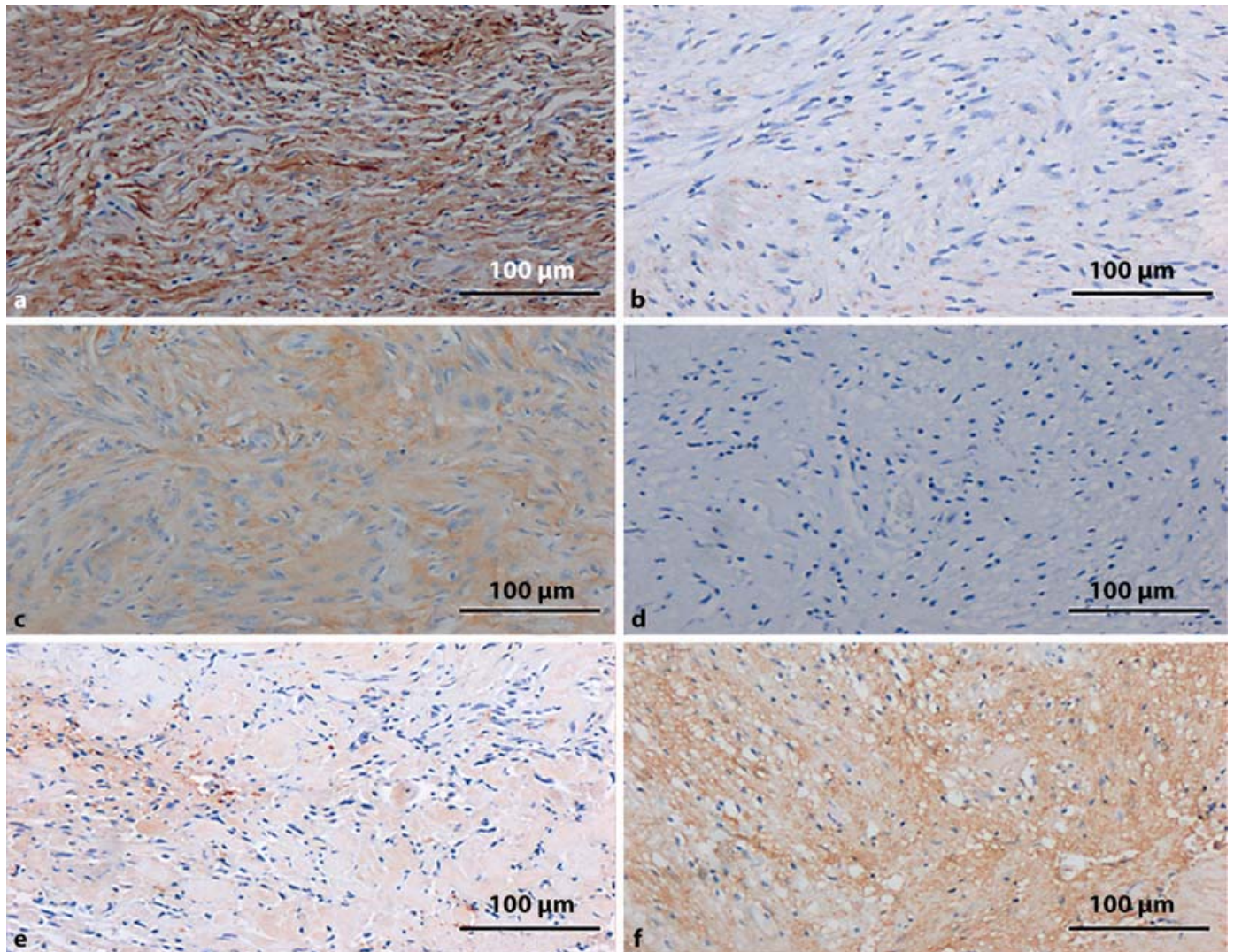


\section{References}

1 Bonneville F, Sarrazin JL, Marsot-Dupuch K, Iffenecker C, Cordoliani YS, Doyon D, Bonneville JF: Unusual lesions of the cerebellopontine angle: a segmental approach. Radiographics 2001;21:419-438.

2 Schaller B, Heilbronner R, Pfaltz CR, Probst RR, Gratzl O: Preoperative and postoperative auditory and facial nerve function in cerebellopontine angle meningiomas. Otolaryngol Head Neck Surg 1995;112:228-234.

3 Chen AF, Samy RN, Gantz BJ: Cerebellopontine angle tumor composed of Schwann and meningeal proliferations. Arch Otolaryngol Head Neck Surg 2001;127:1385-1389.

4 Evans DG, Huson SM, Donnai D, Neary W, Blair V, Teare D, Newton V, Strachan T, Ramsden R, Harris R: A genetic study of type 2 neurofibromatosis in the United Kingdom. I. Prevalence, mutation rate, fitness, and confirmation of maternal transmission effect on severity. J Med Genet 1992;29:841-846.

5 Tokunaga T, Shigemori M, Hirohata M, Sugita Y, Miyagi J, Kuramoto S: Multiple primary brain tumors of different histological types - report of two cases. Neurol Med Chir (Tokyo) 1991;31:141-145.

6 Tsukamoto H, Hikita T, Takaki T: Cerebellopontine angle meningioma associated with cranial accessory nerve neurinoma - case report. Neurol Med Chir (Tokyo) 1994;34:225-229.

7 Maiuri F, Cappabianca P, Iaconetta G, Esposito F, Messina A: Simultaneous presentation of meningiomas with other intracranial tumours. Br J Neurosurg 2005; 19:368-375

8 Whittle IR, Smith C, Navoo P, Collie D: Meningiomas. Lancet 2004;363:15351543.

9 Beppu T, Yoshida Y, Wada T, Arai H, Suzuki M, Kuroda K, Ogawa A: Trochlear and abducens nerve neurinomas accompanied by a cerebellopontine angle meningioma - case report. Neurol Med Chir (Tokyo) 1997;37:416-421.

10 Elizabeth J, Menon G, Nair S, Radhakrishnan VV: Mixed tumour of schwannoma and meningioma in a patient with neurofibromatosis-2: a case report. Neurol India 2001;49:398-400.

11 Gerber PA, Antal AS, Neumann NJ, Homey B, Matuschek C, Peiper M, Budach W, Bolke E: Neurofibromatosis. Eur J Med Res 2009;14:102-105.

12 McClatchey AI: Neurofibromatosis. Annu Rev Pathol 2007;2:191-216.

13 Evans DG: Neurofibromatosis type 2 (NF2): a clinical and molecular review. Orphanet J Rare Dis 2009;4:16.

14 Little MP, de Vathaire F, Shamsaldin A, Oberlin O, Campbell S, Grimaud E, Chavaudra J, Haylock RG, Muirhead CR: Risks of brain tumour following treatment for cancer in childhood: modification by genetic factors, radiotherapy and chemotherapy. Int J Cancer 1998;78:269-275.

15 Gardner WJ, Turner OA: Multiple intracranial tumors. JAMA 1939;113:111-113.

16 Izci Y, Secer HI, Gonul E, Onguru O: Simultaneously occurring vestibular schwannoma and meningioma in the cerebellopontine angle: case report and literature review. Clin Neuropathol 2007;26:219-223.

17 Thomassin JM, Pellet W, Abram D, Korchia D: [Tumors of the cerebellopontine angle. Fortuitous association of meningioma and neurinoma]. Ann Otolaryngol Chir Cervicofac 1991;108:248-252.

18 Wilms G, Plets C, Goossens L, Goffin J, Vanwambeke K: The radiological differentiation of acoustic neurinoma and meningioma occurring together in the cerebellopontine angle. Neurosurgery 1992;30:443-445; discussion 445-446.

19 Chandra PS, Hegde T: A case of coexisting cerebellopontine angle meningioma and schwannoma. Neurol India 2000;48:198.

20 Schaller B: [Cerebellopontine angle surgery. Part 2: Specific remarks]. HNO 2003;51:375-385.

21 Kondziolka D, Flickinger JC, Lunsford LD: The principles of skull base radiosurgery. Neurosurg Focus 2008;24:E11.

22 Vernimmen FJ, Slabbert JP: Assessment of the alpha/beta ratios for arteriovenous malformations, meningiomas, acoustic neuromas, and the optic chiasma. Int J Radiat Biol 2010;86:486-498. 